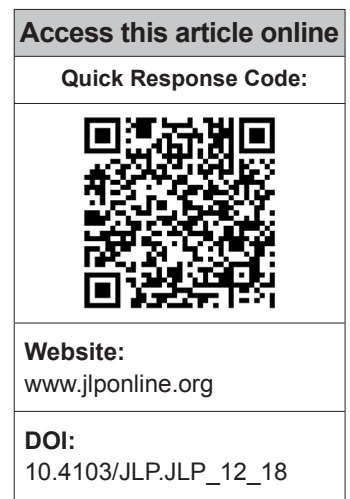

Departments of Clinical Virology, ${ }^{1}$ Molecular and Cellular Medicine and

${ }^{2}$ Hepatology, Institute of Liver and Biliary Sciences, New Delhi, India

Address for correspondence:

Dr. Ekta Gupta, Department of Clinical Virology, Institute of Liver and Biliary Sciences, New Delhi, India. E-mail: ektagaurisha@ gmail.com

Submission: 24-01-2018 Accepted: 02-05-2018

\title{
Evaluation of impact of occult hepatitis $B$ infection in chronic HCV-infected patients: A retrospective cohort study
}

\author{
Mohit Bhatia, Ekta Gupta, Manish C. Choudhary ${ }^{1}$, Ankur Jindal ${ }^{2}$, Shiv Kumar Sarin ${ }^{2}$
}

\section{Abstract:}

CONTEXT: Occult hepatitis B infection (OBI) may contribute to liver damage and variable therapeutic response in patients with chronic hepatitis $\mathrm{C}(\mathrm{CHC})$ infection.

AIMS: To study the prevalence of $\mathrm{OBI}$ and to evaluate its impact and/or that of anti-HBc total seropositivity on clinical outcomes and response to directly acting antiviral (DAA) therapy in $\mathrm{CHC}$-infected patients.

SETTINGS AND DESIGN: A retrospective cohort study was conducted in a tertiary care liver hospital from January to May 2017.

SUBJECTS AND METHODS: Eighty HBsAg-negative CHC patients who were initiated on DAA therapy were retrospectively included. Archived pretreatment baseline plasma samples were retrieved and tested for quantitative HBV DNA, anti-HBs, and anti-HBc total antibodies. HCV RNA, genotype, clinical, biochemical and histopathological parameters \& treatment response data were obtained from the hospital information system.

STATISTICAL ANALYSIS USED: Comparison of continuous variables was done by Mann-Whitney and Kruskal-Wallis tests and categorical variables by Fisher's exact test or Pearson's Chi-square test.

RESULTS: Prevalence of OBI was $1.25 \%$. Anti-HBc total positivity was seen in $25 \%$ patients. Based on anti-HBc total status, patients were categorized into two groups namely Group 1 (anti-HBc positive) and Group 2 (anti-HBc negative). Group 1 patients were further categorized into three subgroups based on signal/cutoff (S/Co) of $\mathrm{HBc}$ total antibody semi-quantitative values. $\mathrm{HBc}$ total antibody levels did not influence the severity of $\mathrm{CHC}$ disease. Comparative evaluation of parameters such as median $\log _{10}$ baseline RNA ( $P=0.929$ and 0.464), median alanine aminotransferase (ALT 0) $(P=0.519$ and 0.449), ALT at 12 weeks $(P=0.875$ and 0.594$)$, sustained virological response (SVR) at 12 weeks $(P=0.405$ and 0.263$)$ and SVR at 24 weeks $(P=0.265$ and 0.625$)$ between Groups 1 and 2 and among three categories within Group 1, respectively, were not found to be statistically significant.

CONCLUSIONS: Very low prevalence of $\mathrm{OBI}$ was seen in $\mathrm{CHC}$ patients. $\mathrm{HBc}$ total antibody levels did not influence clinical outcome and response to DAA therapy in this cohort.

Key words:

Chronic hepatitis C, directly acting antivirals, occult hepatitis B infection

\section{Introduction}

Ocul ccult hepatitis B infection (OBI) is defined as the existence of low-level DNA in the serum/plasma $(<200 \mathrm{IU} / \mathrm{ml})$, cells of the lymphatic system and/or hepatic

This is an open access journal, and articles are distributed under the terms of the Creative Commons Attribution-NonCommercial-ShareAlike 4.0 License, which allows others to remix, tweak, and build upon the work non-commercially, as long as appropriate credit is given and the new creations are licensed under the identical terms.

For reprints contact: reprints@medknow.com tissue in patients with serological markers of previous infection (anti-HBc and/ or anti-HBs positive) and the absence of serum HBsAg. ${ }^{[1]}$ On the basis of HBV antibodies' profile, OBI may be classified as seropositive and seronegative. While the former is positive for hepatitis B core and/or antibodies, the latter is negative for

How to cite this article: Bhatia M, Gupta E, Choudhary MC, Jindal A, Sarin SK. Evaluation of impact of occult hepatitis B infection in chronic HCVinfected patients: A retrospective cohort study. J Lab Physicians 2018;10:304-8. 
all markers of HBV infection besides very low amount of HBV DNA $(<200 \mathrm{IU} / \mathrm{ml}){ }^{[2]}$

Varied prevalence of OBI ranging from $<1 \%$ to as high as $87 \%$ has been reported from different parts of the world. ${ }^{[3]}$ Although the prevalence of OBI in patients with chronic hepatitis varies, the highest prevalence is among those suffering from chronic hepatitis $\mathrm{C}(\mathrm{CHC}){ }^{[4]}$ The incidence of $\mathrm{OBI}$ in $\mathrm{HCV}$ patients varies greatly ranging from $0 \%$ to $52 \% .{ }^{[5]}$ The clinical impact of OBI on the natural history of $\mathrm{CHC}$ has been extensively investigated, but the available data are conflicting and do not allow for conclusions to be drawn on this topic. ${ }^{[6]}$ The risk of developing OBI is very high in HIV-positive individuals. Variable prevalence rates ranging from $0 \%$ to $89.5 \%$ have been reported in this high-risk cohort from different parts of the world. High incidence of OBI has been reported among HIV-positive patients in countries such as South Africa, Iran, Lebanon, and the UK. ${ }^{[7]}$ There are few reports available on OBI/HIV coinfection from India. ${ }^{[8,9]}$ The impact of OBI on the prognosis of HIV-positive patients is unclear. Lamivudine seems inadequate for long-term prevention of hepatic flares in anti-HIV-positive patients with OBI and possibly in reducing the risk of HBV oncogenicity. ${ }^{[10]}$

Many studies have evaluated the impact of OBI on therapeutic response to alpha interferon (IFN) in CHC infection. The presence of OBI has been associated with a poor therapeutic response to alpha IFN in many of these studies. ${ }^{[1,12]}$ Few studies have also evaluated the impact of OBI on treatment response to Peg-IFN $\alpha$ and ribavirin combination therapy in patients suffering from $\mathrm{CHC}$ infection. However, the results of most of these studies have been largely inconclusive..$^{[4,13-16]}$

We aimed to study the prevalence of $\mathrm{OBI}$ and evaluate its impact and/or that of anti-HBc total seropositivity on clinical outcomes and response to directly acting antiviral (DAA) therapy in patients suffering from $\mathrm{CHC}$. To the best of our knowledge, no studies have been conducted till date to evaluate the impact of OBI on treatment response to DAA therapy in $\mathrm{CHC}$-infected patients.

\section{Subjects and Methods}

A retrospective cohort study was conducted in a tertiary care liver hospital from January to May 2017. Approval to conduct this study was obtained from the Institutional Ethics Committee of Institute of Liver and Biliary Sciences, New Delhi, India (Reference number IEC/2017/51/NA05). Eighty HBsAg-negative CHC-infected adult patients who were initiated on DAA therapy were retrospectively included in the study. HBsAg-reactive $\mathrm{CHC}$ patients, patients concomitantly infected with HAV, HDV, $\mathrm{HEV}, \mathrm{HIV}$, acute HCV-infected patients and pregnant females were excluded from the study. Archived pretreatment plasma samples were retrieved and tested for quantitative HBV DNA by real-time polymerase chain reaction (PCR) (COBAS TaqMan 48 Analyzer, Roche Molecular Diagnostics, Germany; linear range: $29-1.10 \times 10^{8} \mathrm{IU} / \mathrm{ml}$; LOD: <6.0 IU/ml). The presence of anti-HBs, anti-HBc total antibodies was tested for by chemiluminescence assay (Architect i1000SR, Abbott diagnostics) as per the manufacturer's guidelines. Data regarding HCV RNA, genotype, clinical, biochemical, histopathological parameters and treatment response were obtained from the hospital information system.

Categorical variables were presented as proportions while continuous variables were either presented as mean with standard deviation (SD) or median with range. Comparison of continuous variables was done by Mann-Whitney and Kruskal-Wallis tests for two and three independent variables, respectively and categorical variables by Fisher's exact test or Pearson's Chi-square test. All statistical tools were two-tailed and a significant level $P<0.05$ was used. All statistical tests were performed using SPSS v22.0 (Armonk IBM Corp., N.Y., U.S.A).

\section{Results}

\section{Baseline characteristics}

The study population consisted of $57.5 \%(46 / 80)$ males and $42.5 \%(34 / 80)$ females with a mean age \pm SD. of $52.06 \pm 11.36$ years. Seropositive OBI was detected in $40 \%(32 / 80)$ patients. Plasma samples of $14(17.5 \%)$, $12(15 \%)$, and $6(7.5 \%)$ of these patients were, respectively, found to be reactive for anti-HBc, anti-HBs and both antibodies. HBV DNA (34 IU/ml) could be detected in the plasma sample of only one patient by quantitative PCR and therefore, the prevalence of OBI was $1.25 \%$.

\section{HCV genotype distribution}

Information regarding HCV genotype of 59 out of 80 patients could be retrieved from the hospital information system. Genotype-wise distribution of the study population revealed that genotype 3 $(n=43 ; 72.90 \%)$ followed by genotype $1(n=14 ; 23.70 \%)$ was most common. HCV genotype 4 infection was observed in $2(3.4 \%)$ patients.

\section{$\mathrm{HBc}$ total seropositivity}

The study population was divided into two groups namely Group 1 (anti-HBc total positive) $n=20(25 \%)$ and Group 2 (anti-HBc total negative) $n=60(75 \%)$ based on the seropositivity toward anti-HBc total antibody, which is an indirect marker for exposure to HBV infection. Group 1 was further categorized into three subgroups 
based on signal to cutoff ratio (S/Co) for anti-HBc total antibody levels. The aforementioned groups and subgroups did not significantly differ $(P>0.05)$ with each other in terms of clinical, biochemical, and histopathological parameters, depicting that amount of $\mathrm{HBc}$ total antibody present in this cohort had no influence on the severity of HCV disease. These results have been depicted in Tables 1 and 2, respectively. Table 3 shows that no statistically significant association $(P>0.05)$ was found between HCV genotype and anti-HBc total seropositivity, clearly indicating that $\mathrm{HBV}$ exposure was independent of $\mathrm{HCV}$ genotype in $\mathrm{CHC}$ patients.

\section{Anti-HCV therapy and response to treatment}

All patients were treated with DAAs. While $92.5 \%(74 / 80)$ patients were treated with sofosbuvir, $5 \%(4 / 80)$ received sofosbuvir + daclatasvir therapy. Sofosbuvir + simeprevir were used for treating $2.5 \%(2 / 80)$ patients. IFN therapy was administered before starting treatment with DAA in $36.25 \%(29 / 80)$ patients.

Sustained virological response at 12 and 24 weeks (SVR 12 and SVR 24), respectively, was attained by $84.2 \%(16 / 19)$ and $93.8 \%(15 / 16)$ patients belonging to Group 1. Similarly, 91.2\% (52/57) and 79.2\% (38/48) patients belonging to Group 2 attained SVR 12 and 24, respectively. As depicted in Table 1, no statistically significant difference was observed between Groups 1 and 2 with respect to SVR 12 and 24, respectively $(P=0.405$ and 0.265$)$. Likewise, attainment of SVR was not influenced by S/Co for anti-HBc total antibody levels as shown in Table 2. Among Group 1 patients, 80\% (16/20) responded to treatment and 20\% (4/20) were relapsers.

Table 1: Comparative evaluation of clinical, biochemical, histopathological and treatment response parameters based on anti-HBc reactivity

\begin{tabular}{|c|c|c|c|}
\hline $\begin{array}{l}\text { Category } \\
\text { Parameter }\end{array}$ & Group 1 & Group 2 & $P$ \\
\hline $\begin{array}{l}\log _{10} \text { baseline RNA, } \\
\text { median (range) }\end{array}$ & $\begin{array}{c}5.833 \\
(1.799-7.093)\end{array}$ & $\begin{array}{c}5.847 \\
(2.630-6.962)\end{array}$ & 0.929 \\
\hline Total bilirubin (0 weeks) & $0.85(0.1-4.3)$ & $1.1(0.4-6)$ & 0.378 \\
\hline Total bilirubin (end of $\mathrm{Rx}$ ) & $0.85(0-4)$ & $1.2(0-7)$ & 0.434 \\
\hline ALT (0 weeks) & $59.50(19-246)$ & $63(23-612)$ & 0.519 \\
\hline ALT (end of Rx) & $27.50(17-89)$ & $30.50(12-147)$ & 0.875 \\
\hline SVR $12, n / N(\%)$ & $16 / 19(84.2)$ & $52 / 57(91.2)$ & 0.405 \\
\hline SVR $24, n / N(\%)$ & $15 / 16(93.8)$ & $38 / 48(79.2)$ & 0.265 \\
\hline $\begin{array}{l}\text { Ishak HAI, } \\
\text { median (range) }\end{array}$ & $6(2-13)$ & $7(5-8)$ & 0.530 \\
\hline $\begin{array}{l}\text { Fibrosis score, } \\
\text { median (range) }\end{array}$ & $5(1-6)$ & $3(2-6)$ & 0.530 \\
\hline Cirrhosis, $n / N(\%)$ & $18 / 20(90)$ & $45 / 60(75)$ & 0.156 \\
\hline $\begin{array}{l}\text { Hepatocellular } \\
\text { carcinoma, } n / N(\%)\end{array}$ & $0 / 20(0)$ & $0 / 60(60)$ & - \\
\hline Liver transplant, $n / N(\%)$ & $0 / 20(0)$ & 2/60 (3.3) & 1.000 \\
\hline
\end{tabular}

$\mathrm{Rx}=$ Treatment, $\mathrm{ALT}=$ Alanine aminotransferase, SVR 12=Sustained virological response 12 weeks following end of treatment, SVR 24=Sustained virological response 24 weeks following end of treatment, $\mathrm{HAl}=$ Hepatic activity index
Similarly, 85\% (51/60) and 15\% (9/60) of Group 2 patients were treatment responders and relapsers, respectively. Analysis of genotype versus treatment response revealed that 39/43 (90.7\%) and 13/14 (92.8\%) HCV genotypes 3 and 1 infected patients, respectively, attained SVR and this difference in proportion was not found to be statistically significant $(P=1.000)$.

\section{Discussion}

The present study showed a very low prevalence $(1.25 \%)$ of OBI in CHC. Marked variation in the prevalence of OBI ranging from $1.5 \%$ to $39.2 \%$ has been observed in patients suffering from $\mathrm{CHC}$ infection. ${ }^{[17-22]}$ One of the major reasons cited to explain these aberrant findings is type of sample used (liver biopsy vs. plasma/serum). ${ }^{[18]}$ The analysis of liver DNA extracts represents the gold standard for evaluation of OBI as the detection of HBV DNA in liver tissue of HBsAg-negative subjects is considered to have high sensitivity and specificity. However, serum or plasma analysis may be taken into account in the absence of liver biopsy specimens. Owing to several advantages such as easy availability, high specificity and moderate sensitivity of detection of HBV DNA, plasma samples have frequently been tested in several studies conducted on OBI. ${ }^{[23]}$ Several other explanations have also been given to understand wide variation in the prevalence of OBI among $\mathrm{CHC}$-infected patients, which include difference in sample size of the study populations, demographics, immunologic status of the study population, endemicity of HBV infection, levels of viral DNA in blood, sampling conditions and types of diagnostic tools used. ${ }^{[18]}$

Anti-HBc is considered to be an indicator of both past and persistent $\mathrm{HBV}$ infection. ${ }^{[20]}$ The clinical significance of the anti-HBc quantitative (qAnti-HBc) level remains largely unknown. Positive correlation between qAnti-HBc, transaminase levels and liver inflammation has been hypothesized by several authors. ${ }^{[24-26]}$ Predictive value of pretreatment quantification of qAnti-HBc levels for the treatment response in CHB patients on Peg-IFN therapy has also been studied by Hou et al. ${ }^{[27]}$ While the exact underlying mechanism of the positive correlation between serum qAnti-HBc level, serum alanine aminotransferase (ALT) level and inflammation severity remains to be examined, a possible mechanistic explanation for this association is that all of these features are determined by the host's immune responses. Although HBV is not directly cytopathic to hepatocytes, tissue-damaging inflammation occurs when the host's immune system attacks liver cells. ALT and HBcAg can be released from damaged infected hepatocytes into the bloodstream. An increase in the serum ALT level causes potent antigenic stimulation of B-cells, resulting in an increase 
Table 2: Comparative evaluation based on signal/cutoff of $\mathrm{HBc}$ total antibody semi-quantitative values of anti-HBc

\begin{tabular}{|c|c|c|c|c|}
\hline $\begin{array}{l}\text { Core total S/Co category } \\
\text { Parameter }\end{array}$ & Category 1 (2-4.99) & Category 2 (5-9.99) & Category $3(\geq 10)$ & $\boldsymbol{P}$ \\
\hline $\log _{10}$ baseline RNA, median (range) & $5.833(5.307-6.657)$ & $5.968(1.799-7.093)$ & $5.375(4.307-6.796)$ & 0.464 \\
\hline Total bilirubin (0 weeks) & $0.90(0.1-4.3)$ & $2.1(0.6-3.6)$ & $0.80(0.5-2)$ & 0.257 \\
\hline Total bilirubin (12 weeks) & $1.8(1-4)$ & $1.8(1-2)$ & $0.80(0-1)$ & 0.128 \\
\hline ALT (0 weeks) & $53.50(19-246)$ & $50(28-64)$ & $71.50(31-172)$ & 0.449 \\
\hline $\mathrm{ALT}$ (end of Rx) & $31.50(18-89)$ & $36(27-45)$ & $26(17-60)$ & 0.594 \\
\hline SVR $12, n / N(\%)$ & $4 / 6(66.7)$ & $5 / 6(83.3)$ & $7 / 7(100)$ & 0.263 \\
\hline SVR $24, n / N(\%)$ & $5 / 5(100)$ & $4 / 5(80)$ & $6 / 6(100)$ & 0.625 \\
\hline Ishak HAI, median (range) & $8(6-13)$ & $4(2-6)$ & $5(5-5)$ & 0.140 \\
\hline Fibrosis score, median (range) & $4(2-5)$ & $3.50(1-6)$ & $5.50(5-6)$ & 0.475 \\
\hline Cirrhosis, $n / N(\%)$ & $6 / 6(100)$ & $5 / 6(83.3)$ & $7 / 8(87.5)$ & 1.000 \\
\hline Hepatocellular carcinoma, $n / N(\%)$ & $6 / 6(100)$ & $6 / 6(100)$ & $8 / 8(100)$ & - \\
\hline Liver transplant, $n / N(\%)$ & $0 / 6(0)$ & $0 / 6(0)$ & $0 / 8(0)$ & - \\
\hline
\end{tabular}

$\mathrm{Rx}=$ Treatment, $\mathrm{ALT}=\mathrm{Alanine}$ aminotransferase, SVR 12=Sustained virological response 12 weeks following end of treatment, SVR $24=$ Sustained virological response 24 weeks following end of treatment, $\mathrm{HAl}=\mathrm{Hepatic}$ activity index, $\mathrm{S} / \mathrm{Co}=\mathrm{Signal} / \mathrm{cutoff}$

Table 3: Association between HCV genotype and anti-HBc total seropositivity

\begin{tabular}{lccc}
\hline HCV genotype & Group 1, $(n / 18: \%)^{*}$ & Group 2, $(n / 41: \%)^{*}$ & $P$ \\
\hline 1 & $3(16.70)$ & $11(26.80)$ & 0.52 \\
3 & $13(72.20)$ & $30(73.20)$ & 1.00 \\
4 & $2(11.10)$ & $0(0.0)$ & 0.09 \\
\hline
\end{tabular}

*Information regarding HCV genotype for 18 and 41, Group 1 and 2 patients, respectively, could be retrieved from hospital information system

in the serum qAnti-HBc level. However, there is a lack of direct evidence from liver biopsies to confirm these results. ${ }^{[24]}$

In the present study, analysis of clinical, biochemical, histopathological and treatment response parameters based on seropositivity and semiquantitative estimation of anti-HBc did not yield statistically significant results. These results are in agreement with those obtained in the studies conducted by Chen et al. and Mahmoud et al. ${ }^{[17,19]}$

Few treatment trials of $\mathrm{HBV} / \mathrm{HCV}$ coinfection have been conducted and published. The results of these trials do not point towards any significant association between $\mathrm{HBV} / \mathrm{HCV}$ coinfection and adverse treatment outcomes in comparison to $\mathrm{HCV}$-monoinfected patients. In studies conducted by Liu et al. Hung et al., and Chuang et al., similar SVR rates were obtained in patients with $\mathrm{HBV} / \mathrm{HCV}$ coinfection and those with HCV infection alone. ${ }^{[28-30]}$

There were several limitations of our study such as small sample size, retrospective instead of prospective study design and use of plasma in place of liver biopsy samples for the detection of HBV DNA.

\section{Conclusions}

Very low prevalence of OBI was seen in $\mathrm{CHC}$ patients and anti-HBc total antibody levels did not influence clinical outcome and response to DAA therapy in this cohort. Although our study findings are largely inconclusive, keeping in mind the various limitations of our study and paucity of literature, more number of prospective studies should be conducted to further explore this seemingly enigmatic issue.

\section{Acknowledgment}

We would like to acknowledge the technical staff of Department of Clinical Virology, Institute of Liver and Biliary Sciences, New Delhi, India.

\section{Financial support and sponsorship Nil.}

\section{Conflicts of interest}

There are no conflicts of interest.

\section{References}

1. Raimondo G, Allain JP, Brunetto MR, Buendia MA, Chen DS, Colombo M, et al. Statements from the Taormina expert meeting on occult hepatitis B virus infection. J Hepatol 2008;49:652-7.

2. Bhattacharya H, Bhattacharya D, Roy S, Sugunan AP. Occult hepatitis $\mathrm{B}$ infection among individuals belonging to the aboriginal Nicobarese tribe of India. J Infect Dev Ctries 2014;8:1630-5.

3. Yuen MF, Lee CK, Wong DK, Fung J, Hung I, Hsu A, et al. Prevalence of occult hepatitis B infection in a highly endemic area for chronic hepatitis B: A study of a large blood donor population. Gut 2010;59:1389-93.

4. Emara MH, El-Gammal NE, Mohamed LA, Bahgat MM. Occult hepatitis B infection in Egyptian chronic hepatitis C patients: Prevalence, impact on pegylated interferon/ribavirin therapy. Virol J 2010;7:324.

5. Shavakhi A, Norinayer B, Esteghamat FS, Seghatoleslami M, Khodadustan M, Somi MH, et al. Occult hepatitis B among Iranian hepatitis C patients. J Res Med Sci 2009;14:13-7.

6. Fernandez-Rodriguez CM, Gutierrez ML, Lledó JL, Casas ML. Influence of occult hepatitis B virus infection in chronic hepatitis C outcomes. World J Gastroenterol 2011;17:1558-62.

7. Saha D, Pal A, Sarkar N, Das D, Blackard JT, Guha SK, et al. Occult 
hepatitis B virus infection in HIV positive patients at a tertiary healthcare unit in Eastern India. PLoS One 2017;12:e0179035.

8. Gupta S, Singh S. Occult hepatitis B virus infection in ART-naive HIV-infected patients seen at a tertiary care centre in North India. BMC Infect Dis 2010;10:53.

9. Rai RR, Mathur A, Mathur D, Udawat HP, Nepalia S, Nijhawan S, et al. Prevalence of occult hepatitis B\&amp; C in HIV patients infected through sexual transmission. Trop Gastroenterol 2007;28:19-23.

10. Sagnelli E, Pisaturo M, Martini S, Filippini P, Sagnelli C, Coppola N, et al. Clinical impact of occult hepatitis B virus infection in immunosuppressed patients. World J Hepatol 2014;6:384-93.

11. Fukuda R, Ishimura N, Niigaki M, Hamamoto $S$, Satoh $S$, Tanaka S, et al. Serologically silent hepatitis B virus coinfection in patients with hepatitis $C$ virus-associated chronic liver disease: Clinical and virological significance. J Med Virol 1999;58:201-7.

12. Cacciola I, Pollicino T, Squadrito G, Cerenzia G, Orlando ME, Raimondo G, et al. Occult hepatitis B virus infection in patients with chronic hepatitis C liver disease. N Engl J Med 1999;341:22-6.

13. Georgiadou SP, Zachou K, Rigopoulou E, Liaskos C, Mina P, Gerovasilis F, et al. Occult hepatitis B virus infection in Greek patients with chronic hepatitis $C$ and in patients with diverse nonviral hepatic diseases. J Viral Hepat 2004;11:358-65.

14. Fabris P, Brown D, Tositti G, Bozzola L, Giordani MT, Bevilacqua $\mathrm{P}$, et al. Occult hepatitis $\mathrm{B}$ virus infection does not affect liver histology or response to therapy with interferon alpha and ribavirin in intravenous drug users with chronic hepatitis $C$. J Clin Virol 2004;29:160-6.

15. Kao JH, Chen PJ, Lai MY, Chen DS. Occult hepatitis B virus infection and clinical outcomes of patients with chronic hepatitis C. J Clin Microbiol 2002;40:4068-71.

16. Mrani S, Chemin I, Menouar K, Guillaud O, Pradat P, Borghi G, et al. Occult HBV infection may represent a major risk factor of non-response to antiviral therapy of chronic hepatitis C. J Med Virol 2007;79:1075-81.

17. Chen HY, Su TH, Tseng TC, Yang WT, Chen TC, Chen PJ, et al. Impact of occult hepatitis B on the clinical outcomes of patients with chronic hepatitis $C$ virus infection: A 10-year follow-up. J Formos Med Assoc 2017;116:697-704.

18. Mandour M, Nemr N, Shehata A, Kishk R, Badran D, Hawass N, et al. Occult HBV infection status among chronic hepatitis $C$ and hemodialysis patients in Northeastern Egypt: Regional and national overview. Rev Soc Bras Med Trop 2015;48:258-64.
19. Mahmoud OA, Ghazal AA, Metwally DE, Shamseya MM, Hamdallah HM. Detection of occult hepatitis B virus among chronic hepatitis C patients. Alexandria J Med 2016;52:115-23.

20. Squadrito G, Cacciola I, Alibrandi A, Pollicino T, Raimondo G. Impact of occult hepatitis B virus infection on the outcome of chronic hepatitis C. J Hepatol 2013;59:696-700.

21. Sarvanan S, Madhavan V, Murugavel KG, Balakrishnan P, Solomon SS, Subashini D, et al. Occult hepatitis B virus infection in a cohort of liver disease patients with chronic hepatitis C: A significant association of HCV genotype $1 \mathrm{~b}$ in South India. J Gastroenterol Hepatol 2013;2:692-5.

22. Caviglia GP, Abate ML, Manzini P, Danielle F, Ciancio A, Rosso C, et al. Occult hepatitis B virus infection in patients with chronic hepatitis $C$ treated with antiviral therapy. Hepat Mon 2012;12:e7292.

23. Raimondo G, Caccamo G, Filomia R, Pollicino T. Occult HBV infection. Semin Immunopathol 2013;35:39-52.

24. Li MR, Lu JH, Ye LH, Sun XL, Zheng YH, Liu ZQ, et al. Quantitative hepatitis B core antibody level is associated with inflammatory activity in treatment-naïve chronic hepatitis B patients. Medicine (Baltimore) 2016;95:e4422.

25. Yuan Q, Song LW, Cavallone D, Moriconi F, Cherubini B, Colombatto $\mathrm{P}$, et al. Total hepatitis B core antigen antibody, a quantitative non-invasive marker of hepatitis B virus induced liver disease. PLoS One 2015;10:e130209.

26. Zhang $\mathrm{M}, \mathrm{Wu} \mathrm{R}$, Jiang J, Minuk GY, Niu J. The presence of hepatitis $\mathrm{B}$ core antibody is associated with more advanced liver disease in alcoholic patients with cirrhosis. Alcohol 2013;47:553-8.

27. Hou FQ, Song LW, Yuan Q, Fang LL, Ge SX, Zhang J, et al. Quantitative hepatitis B core antibody level is a new predictor for treatment response in HBeAg-positive chronic hepatitis B patients receiving peginterferon. Theranostics 2015;5:218-26.

28. Liu CJ, Chen PJ, Lai MY, Kao JH, Jeng YM, Chen DS, et al. Ribavirin and interferon is effective for hepatitis $C$ virus clearance in hepatitis B and C dually infected patients. Hepatology 2003;37:568-76.

29. Hung $\mathrm{CH}$, Lee $\mathrm{CM}$, Lu SN, Wang JH, Tung HD, Chen $\mathrm{CH}$, et al. Combination therapy with interferon-alpha and ribavirin in patients with dual hepatitis $B$ and hepatitis $C$ virus infection. J Gastroenterol Hepatol 2005;20:727-32.

30. Chuang WL, Dai CY, Chang WY, Lee LP, Lin ZY, Chen SC, et al. Viral interaction and responses in chronic hepatitis $C$ and $\mathrm{B}$ coinfected patients with interferon-alpha plus ribavirin combination therapy. Antivir Ther 2005;10:125-33. 